\title{
Киноиндустрия сегодня: импульсы и барьеры развития
}

А.А. ШИНАХОВ, Кабардино-Балкарский государственный университет им. Х. М. Бербекова, Нальчик. E-mail: blackxs27@gmail.com

Исследование посвящено выявлению импульсов развития отечественной киноиндустрии в контексте преодоления барьеров, обозначившихся в результате глобализации кинобизнеса и трансформации структуры отрасли в рыночных условиях. Особое внимание уделяется исследованию специфики денежных потоков кинопроекта, на базе которого обоснован подход к комплексной оценке его финансового результата. Проведен анализ ситуации в отрасли с использованием показателей динамики кассовых сборов и рыночной концентрации, а также метода балльной оценки. Изучены последствия от возможной сделки крупнейших кинокомпаний «Уолт Дисней» и «20-й век Фокс» для российского кинематографа. С целью поддержания отечественного кинопроизводства были предложены следующие меры: квотирование зарубежного дистрибьюторского участия на рынке, максимизация инвестиционной привлекательности на основе открытости информации о проекте с использованием предложенной методики, введение предельного значения кинотеатральной ренты для иностранных прокатчиков.

Ключевые слова: киноиндустрия, кассовые сборы, кинотеатральная рента, денежные потоки, дистрибьютор, рыночная структура, кинопроект

\section{Институциональная структура киноиндустрии}

Киноиндустрия представляет собой комплекс институтов производственной и коммерческой деятельности, которые создают и реализуют специфический продут - кинофильм. Она выступает не только как часть сферы досуга, но и является объектом инвестирования, импульсом переливания капитала, важным доходным активом. Страны, где имеются крупные кинопроизводители, выходящие на мировую арену кинобизнеса, получают экономические выгоды от реализации собственных или совместных проектов. Такое положение создает барьеры для российских производителей кино из-за неспособности конкурировать с крупными фирмами в части как финансирования кинопроизводства, так и его рекламы и продвижения.

Кинобизнес - хотя и затратный и рискованный, но доходный способ инвестирования капитала, что делает его привлекательным для вложений. Тем не менее диапазон потенциальных инвесторов ограничен за счет высокой стоимости участия в проектах. 
Получаемые кассовые и прочие доходы распределяются между участниками кинопроектов, следовательно, превалирование иностранных производителей и дистрибьюторов в отечественной киноиндустрии приводит к утечке капитала за рубеж, снижению интереса к фильмам собственного производства, нехватке финансовых ресурсов для их создания. Ситуация может ухудшиться в связи с изменениями конкурентной среды. Речь идет о возможной покупке кинокомпании «20-й век Фокс» лидером мирового кинопроката фирмой «Уолт Дисней», которая может снизить инвестиционную привлекательность и финансовую самостоятельность российского кинематографа.

Институциональная структура киноиндустрии включает следующие звенья.

Производственные кинокомпании, которые занимаются непосредственно производством фильмов, осуществляют аккумулирование средств продюсеров и несут ответственность за их целевое использование. Они создают условия для производства кино (находят площадки для съемок, приобретают или арендуют оборудование, получают разрешения на съемки, подбирают персонал, проводят съемки и монтаж фильмов, контролируют использование бюджета, находят прокатчика).

Дистрибьюторы (прокатчики) осуществляют прокат фильмов в кинотеатрах и на других площадках, размещают рекламу на ТВ и т.д., проводят постпрокатную дистрибуцию на телевидении и домашних носителях. Вознаграждение дистрибьютор получает в процентах от кассовых сборов, оно может дополняться премиальными.

Киностудии представляют собой площадки для производства кино (съемочные павильоны, оборудование для киносъемок и монтажа и прочие помещения), как правило, они принадлежат производственной компании либо между ними существует долгосрочное соглашение о партнерстве.

Данные организации могут объединяться в единую финансовую группу (холдинг, медиаконгломерат), тем самым образуя производственно-дистрибьюторскую компанию, при этом материнской может выступать как продакшн-студия, так и прокатчик; их функции остаются прежними, изменяется лишь схема распределения доходов и расходов. Такое объединение преобладает в зарубежной киноиндустрии, на российском же 
рынке доминируют независимые продакшн-компании и дистрибьюторы, а несколько производственно-дистрибьюторских компаний чаще всего реализуют свои кинопроекты совместно с производственными фирмами.

\section{Финансовые показатели отрасли}

У киноиндустрии в России с советских времен сохранился технологический базис для организации производства [Ковтонюк, 2016. С. 137], поэтому ее развитие происходит достаточно быстрыми темпами: количество фильмов, вышедших в прокат за последние годы, увеличилось в два раза [Седых, 2017. С. 15], посещаемость кинотеатров стабильно растет [Спивакова, Аракелян, 2016. С. 43]. Однако вклад российского кинематографа в ВВП пока очень низок (менее 0,01\%) [Карпушин, Кулакова, 2015. С. 181]. Барьерами для развития отечественной киноиндустрии выступают низкая окупаемость и невысокая инвестиционная привлекательность проектов [Седых, 2017. С. 15], непредсказуемость финансовых результатов еще больше ограничивает источники финансирования [Тевелева, Татарников, 2013. С. 33].

Отсутствие контроля за использованием производственного бюджета в российском кинопроизводстве приводит к перерасходу средств, что препятствует завершению производства в срок и подрывает инвестиционную привлекательность отрасли [Аракелян, 2016. С. 75]. Одним из способов решения данной проблемы является применение гарантий о завершении производства и соблюдении лимитов выделенных средств на базе внедрения практики completion bond [Спивакова, 2013. С. 132].

На данном этапе ключевую роль в развитии отечественного кинематографа играет государственная поддержка (финансовая помощь в денежном выражении равна половине суммы бюджетов всех российских фильмов), однако она не может в полном объеме удовлетворить потребности в капитале [Борисенко, 2015].

Фонд кино адресно оказывает финансовую помощь отечественному коммерческому кинопроизводству (преимущественно в пользу его лидеров, ежегодно определяемых попечительским советом фонда). Финансирование прочих организаций ограничивается поддержкой не более одного фильма за год. В 2017 г. финансовую помощь фонда получили проекты следующих компаний-лидеров кинопроизводства: «ВБД Груп» - 4 проекта, 
«Дирекция Кино»-1, «Арт Пикчерс Студия»-2, «Кинокомпания СТВ »-4, «Нон-Стоп Продакшн» - 1, «ПРОФИТ»-2, «Студия ТриТэ Н. Михалкова» -1 , «ТаББаК» - 5, «Централ Партнершип» $-1^{1}$.

Присутствие на отечественном кинорынке крупных иностранных дистрибьюторских компаний, функционирующих как глобальные корпорации [Чудкова, 2013. С. 65], обостряет проблему конкуренции. В связи с этим считаем актуальным углубленно рассмотреть финансовые аспекты распределения денежных потоков по кинопроектам, провести анализ структуры кассовых сборов отечественного кинобизнеса, оценить финансовую и рыночную ситуации в текущем и перспективном периодах, предложить меры по сглаживанию влияния иностранных корпораций на развитие отечественного кинопроизводства.

Прибыльность кинопроектов является основным индикатором успешности и инвестиционной привлекательности деятельности кинокомпаний, а также источником дальнейшего расширения производства. Виды, источники и сферы распределения денежных потоков представлены на рисунке.

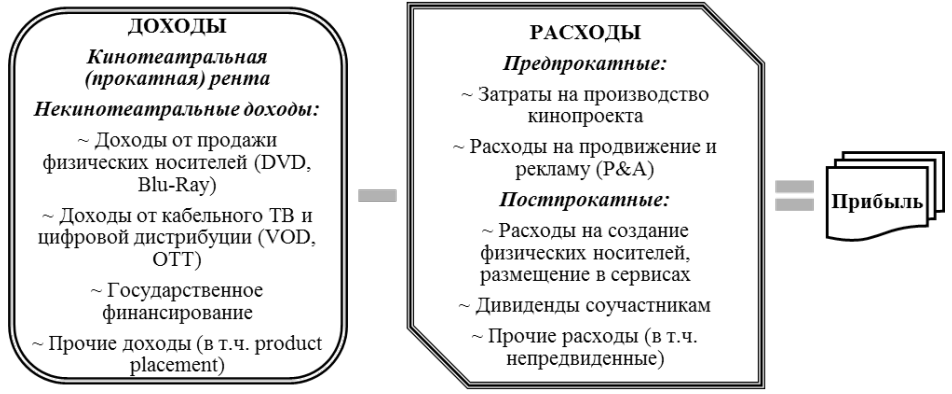

Источник: составлен автором на основе методик Deadline HEBN и Фонда кино.

Методика определения финансового результата кинопроекта

Основным преимуществом предложенной методики комплексной оценки прибыльности кинопроектов являются ее универсальность и точность по сравнению с моделью, принятой

${ }^{1}$ Фонд кино: приказ об утверждении лидеров отечественного кинопроизводства на 2017 год URL: http://www.fond-kino.ru (дата обращения: 01.05.2018). 
в России. Отечественный подход к финансовой оценке кинопроектов был разработан Фондом кино для отбора поддерживаемых фильмов. В этой методике в части доходов выделяются прокатные, продажа прав на TB и DVD, прочие; среди расходов - бюджет производства и бюджет проката. Ее недостатком является рассмотрение проекта только с точки зрения производственных компаний, поскольку в расходах не учитываются трансакционные издержки на размещение в онлайн-сервисах, производство физических носителей, оплата услуг дистрибьюторов и других соучастников, возможные постпрокатные обязательства. Поэтому финансовый результат кинопроекта завышается, искажается его реальная прибыльность.

Предлагаемый автором подход отражает специфику кинофильма как коммерческого продукта, поскольку учитывает нерегулярность денежного потока, обусловливающего постепенное освоение инвестиций по мере реализации всех аспектов проекта [Антонов, 2009. С. 140] элементы сгруппированы не только по времени освоения, но и по субъектам их реализации, тем самым учитывается особенность институционального устройства отечественной киноиндустрии. Что касается зарубежной практики, то состав элементов, включаемых в доходы и расходы, в общем соответствует предлагаемой методике, однако они не группируются, так как там распространены производственно-дистрибьюторские компании, поэтому сложно анализировать деятельность участников проекта обособленно.

Основным источником дохода кинопроекта является кинотеатральная рента, представляющая собой долю в совокупных кассовых сборах, которая перечисляется непосредственно продюсерам и прокатчикам кинофильма. Почему именно рента? Отношения между создателями фильмов и кинотеатрами аналогичны договору временного пользования созданного продукта на определенных условиях. Платой в данном случае выступает часть дохода с каждого проданного билета, которую кинотеатры уплачивают производителям (дистрибьюторам), остаточная доля от продаж составляет уже доходы кинотеатров. Размер ставки кинотеатральной ренты устанавливается в процентах от каждого проданного билета.

В мировой практике сформировались два вида ставок кинотеатральной ренты: дифференцированная и фиксированная, 
величина отчислений с каждого проданного билета определяется индивидуальными соглашениями дистрибьюторов и кинотеатров $^{2}$. При использовании дифференцированной ставки в первые недели проката она устанавливается на повышенном уровне, а затем снижается. Это объясняется более высоким спросом, ценой и, соответственно, объемом продаж билетов в начале проката, что позволяет производителям максимизировать прокатные доходы. Такая практика распространена во всем мире (за исключением нескольких стран), в том числе и в России. Примером киноиндустрии с фиксированной ставкой является китайская, где максимальный размер ренты для иностранных фильмов ограничен в пределах $25 \%$ в течение всего срока проката, лимитированного 30 днями. Это наименьший показатель в мире (исключительно для «Дисней» применяется повышенная ставка в 27\%) ${ }^{3}$. Самый высокий уровень прокатных доходов аккумулируется в США, где величина кинотеатральной ренты равна 50-53\%, в России также действует система 50/50 с распространенной практикой разделения ренты между продюсерами и дистрибьюторами 40/10, в Европе аналогичный показатель составляет 45\% (как свидетельствуют данные европейских ассоциаций кинотеатров, компания «Уолт Дисней» требует для своих кинопроектов увеличения кинотеатральной ренты до 50\% от кассовых сборов),

Сопоставляя сумму кинотеатральной ренты и предпрокатных затрат, можно получить прокатную прибыль (убыток), аналогично прибыли по основной деятельности. Для определения итогового финансового результата по кинопроекту в целом рационально использовать методику, представленную на рисунке, полностью учитывающую все денежные потоки. Наибольший удельный вес среди доходов занимает кинотеатральная рента, соответственно самая существенная доля затрат приходится на производство и рекламу. Однако соотношение некинотеатральных доходов и постпрокатных расходов обычно больше, чем для основных статей, что объясняется более высокой рентабельностью постпрокатных затрат по сравнению с предпрокатными. Иная вариация

\footnotetext{
${ }^{2}$ How is a cinema's box office income distributed? URL: https://stephenfollows.com/howa-cinemas-box-office-income-is-distributed/ (дата обращения: 01.03.2018).

${ }^{3}$ Deadline Hollywood Entertainment Breaking News URL: http://deadline.com/ (дата обращения: 27.12.2017).
} 
говорит о значительном уровне непредвиденных расходов или о неправильном прогнозировании послепрокатного спроса, что случается редко.

Возможна ситуация, когда суммы кинотеатральной ренты не хватает для покрытия предпрокатных расходов. При незначительном разрыве между ними можно покрыть дополнительными доходами остаточные и построкатные расходы, что обеспечит как минимум безубыточность проекта.

В отечественной киноиндустрии среди некинотеатральных доходов наибольший удельный вес занимают государственное финансирование и показ по кабельному ТВ, в отличие от голливудской практики, где основные доходы приносят продажи DVD и Blu-Ray [Эпштейн, 2011. C. 189-190]. Высокий уровень контрафакта в сфере оборота физических носителей в России сводит к минимуму доходность и объемы продаж по данной статье [Аракелян, 2017. С. 51]. Невостребованность старых форматов и стремительное развивитие цифровой дистрибуции говорят о том, что меры по легализации отрасли физических носителей не приведут к желаемому эффекту, поэтому необходимо сосредоточить внимание на поддержании отрасли онлайн-сервисов, а государству - применять более жесткие меры по соблюдению антипиратского законодательства.

Доходность использования кабельного ТВ меньше, чем продажи DVD и Blu-Ray, но телевидение является значимым каналом для продвижения фильма. Доход формируется путем продажи прав на показ фильма; стоимость, количество показов и срок предоставления лицензии прописываются в договоре. С целью максимизации прибыли телеканалы, следуя за зарубежной практикой, стараются приобрести именно эксклюзивное право на показ, тем самым временно обеспечивая монопольную прибыль, поэтому распространена покупка лицензий еще до начала проката фильма. Такой подход довольно рискован, так как кинопроект, возможно, не будет успешным. В России распространена практика участия телеканалов непосредственно в процессе производства фильмов. Тем самым они обеспечивают себе получение прав на показ, а активное рекламирование проекта через собственные телеканалы способствуют продвижению кинофильма.

Информация о прибыльности кинопроекта может быть представлена в виде коэффициента Cash on Cash Return (CoCR), 
используемого в зарубежной практике ${ }^{4}$. Существуют две методики его расчета: первая - путем деления прибыли на совокупные расходы (в \%); вторая - совокупные доходы делятся на расходы, коэффициент характеризует отдачу на каждую единицу вложенных инвестиций (например, 1,5 к 1). Такой формат представления информации позволяет потенциальным инвесторам сравнивать рентабельность различных проектов.

Можно выделить две схемы распределения денежных потоков по кинопроекту. Первая основывается на финансовой взаимосвязи производителя и дистрибьютора (т.е. оба являются частью единой группы), тогда все расходы будет осуществлять материнская компания, она же получает все доходы, распределяя их по внутренним подразделениям. Совокупный финансовый результат проекта остается внутри корпорации.

Вторая строится на договорных отношениях производителя и дистрибьютора, не состоящих в «дочерней» взаимосвязи. Чаще всего такая форма используется при совместном производстве (в том числе международном), при выходе на зарубежный рынок, имеющий ограничительные барьеры входа, или в случае, когда производитель не способен самостоятельно обеспечить продвижение проекта. Тогда расходы между сторонами будут делиться в соответствии с выполняемыми функциями: продакшн-компания осуществляет затраты на производство и рекламу, дистрибьютор принимает на себя расходы на прокат, теле-, видео- и цифровую дистрибуцию, иногда - и часть рекламных. Вознаграждение дистрибьютора представляет собой фиксированный процент от кассовых сборов (в пределах 10-15\%) и премии, которая зависит от степени вовлеченности прокатчика и успешности реализации проекта, а все остальные доходы передаются продюсерам проекта.

\section{Анализ ситуации на рынке и оценка последствий сделки «Дисней»-«Фокс»}

Проведем комплексный анализ рыночной и, в частности, финансовой ситуации в отечественной киноиндустрии, в предположении, что компании «20-й век Фокс» и «Уолт Дисней»

${ }^{4}$ Deadline Hollywood Entertainment Breaking News URL: http://deadline.com/ (дата обращения: 27.12.2017). 
объединятся. Структура кассовых сборов приведена в таблице 1 (указаны дистрибьюторы, доля на рынке которых во всех рассматриваемых периодах превышала 1\%).

\section{Таблица 1. Распределение кассовых сборов в российской киноиндустрии в 2015-2017 гг.}

\begin{tabular}{|c|c|c|c|c|c|c|}
\hline \multirow[b]{2}{*}{ Дистрибьютор } & \multicolumn{2}{|c|}{2015} & \multicolumn{2}{|c|}{2016} & \multicolumn{2}{|c|}{2017} \\
\hline & $\begin{array}{c}\text { Сборы, } \\
\text { млн руб. }\end{array}$ & $\begin{array}{l}\text { Доля на } \\
\text { рынке,\% }\end{array}$ & $\begin{array}{l}\text { Сборы, } \\
\text { млн руб. }\end{array}$ & $\begin{array}{l}\text { Доля на } \\
\text { рынке,\% }\end{array}$ & $\begin{array}{c}\text { Сборы, } \\
\text { млн руб. }\end{array}$ & $\begin{array}{l}\text { Доля на } \\
\text { рынке,\% }\end{array}$ \\
\hline \multirow{2}{*}{$\begin{array}{l}\text { «Уолт Дисней» / } \\
\text { «20-й век Фокс» }\end{array}$} & \multirow{2}{*}{20915,96} & 43,50 & \multirow{2}{*}{24461,11} & 46,35 & \multirow{2}{*}{24617,60} & 42,71 \\
\hline & & $23,8 / 19,7$ & & $29,1 / 17,25$ & & $29,9 / 12,81$ \\
\hline «Юниверсал Пикчерз» & 9480,12 & 19,72 & 6228,08 & 11,80 & 8256,08 & 14,33 \\
\hline $\begin{array}{l}\text { «Каро Премьер» / } \\
\text { «Каропрокат»* }\end{array}$ & 6095,79 & 12,68 & 8519,96 & 16,16 & 8045,25 & 13,96 \\
\hline $\begin{array}{l}\text { «Централ Партнер- } \\
\text { шип»» }\end{array}$ & 5855,59 & 12,18 & 8080,38 & 15,31 & 8018,87 & 13,91 \\
\hline «Наше Кино»* & 2159,68 & 4,49 & 1549,86 & 2,94 & 3066,32 & 5,32 \\
\hline «Вольга»* & 1414,36 & 2,94 & 882,41 & 1,67 & 1196,02 & 2,08 \\
\hline Bazelevs* & 1311,85 & 2,73 & 1034,92 & 1,96 & 1396,66 & 2,42 \\
\hline «Парадиз»* & 645,77 & 1,34 & 907,805 & 1,72 & 812,82 & 1,41 \\
\hline Остальные & 206,11 & 0,43 & 1105,89 & 2,10 & 2224,07 & 3,86 \\
\hline ВСЕГО & 48085,23 & 100 & 52770,41 & 100 & 57633,69 & 100 \\
\hline
\end{tabular}

Источник: данные портала «Кинобизнес сегодня» URL: https://www. kinobusiness.com/ (дата обращения: 17.01.2018).

*Отечественные компании.

Из представленных данных видно, что, несмотря на превышение числа отечественных прокатчиков над иностранными, наибольший удельный вес в кассовых сборах - у последних. Можно отметить устойчивую тенденцию роста рынка: на 9,74\% в 2016 г. и на 9,22\% в 2017 г. Эти показатели динамики совокупных кассовых сборов - одни из самых высоких в мировой киноиндустрии. И самое важное - рост был обеспечен за счет лучшей посещаемости кинотеатров, так как увеличение средней стоимости билета по стране в эти периоды было несущественным (в пределах $1 \%)^{5}$. Среди прокатчиков лидером является «Уолт Дисней», причем его индивидуальная доля растет, а сборы компании «20-й век Фокс», напротив, уменьшаются, что связано с финансовыми проблемами, обусловленными

\footnotetext{
${ }^{5}$ Роль кинотеатров для торговых центров, доля трафика кинотеатров в общем трафике ТРЦ и способы конвертации URL: http://www.rcsc.info/docs/JLL_Presentation_RCSC_final. pdf (дата обращения: 12.02.2018).
} 
сложностью освоения крупнобюджетных фильмов. Это, на наш взгляд, свидетельствует о высокой вероятности поглощения этой фирмы.

Дадим более подробную характеристику дистрибьюторам с учетом специфики их деятельности. «Централ Партершип»крупнейший дистрибьютор российских фильмов, имеет собственную производственную кинокомпанию и киностудию, также занимается дистрибуцией фильмов других производителей (в том числе эксклюзивно иностранных: Paramount Pictures, Lionsgate, Summit Entertainment). В 2017 г. прокатчиком было выпущено 38 фильмов («Трансформеры: последний рыцарь», «Три икса: мировое господство», «Кухня: последняя битва», «Пила-8», «Гуляй, Вася!», «Спасатели Малибу» и др.), из них собственного производства - «Легенда о Коловрате», «Движение вверх» (совместно с кинокомпанией «Студия ТриТэ»); в 2016 г. - всего 33 фильма («Боги Египта», «Черепашки-ниндзя 2», «Стартрек: Бесконечность», «Новогодний корпоратив», «Ла-Ла Ленд», «Звонки» и т.д.), совместного производства «Экипаж» в партнерстве с «Студия ТриТэ», «Викинг» в сотрудничестве с «Дирекция Кино», мультфильм «Бременские разбойники» совместно co Star Media; в 2015 г. был осуществлен прокат 37 фильмов («Терминатор: Генезис», «Миссия невыполнима: Племя изгоев», «Губка Боб в 3D», «Дивергент. Глава 2: Инсургент», «8 лучших свиданий»). По кассовым сборам 12 фильмов прокатчика достигли отметки в 1 млрд руб., три из них - отечественные. Реализуются многожанровые проекты, имеются прочные связи с крупными иностранными производителями, собственное кинопроизводство преимущественно осуществляется в сотрудничестве с другими компаниями. В сфере рекламы упор делается на телевидение в связи с наличием партнерских отношений с крупными телеканалами («Первый», «Россия», НТВ).

«Каро Премьер» / «Каропрокат» состоит из двух дистрибьюторских компаний - «Каро Премьер» является эксклюзивным дистрибьютором кинокомпании Warner Bros., «Каропрокат» занимается прокатом исключительно российских фильмов. В общей сложности компания выпустила в прокат в 2017 г. 26 фильмов («Гоголь. Начало», «Фиксики: большой секрет», «Оно», «Лига справедливости», «Первому игроку приготовиться» и др.); 
в 2016 г. - 25 фильмов («Жених», «Защитники», «Статус: свободен», «Училка», «Отряд самоубийц», «Фантастические твари и где они обитают», «Бэтмен против Супермена: на заре справедливости» и др.), в 2015 г. - 29 («Мафия: игра на выживание», «Одной левой», «Женщины против мужчин», «Безумный Макс», «Фокус», «Разлом Сан-Андреас», «Стажер» и т.д.). Собственное производство осуществляется через дочернюю фирму «Каро Продакшн», вышедшие фильмы - «Геймеры» (телевизионный многосерийный) (2012 г.), «Первые» (2017 г.), «Полное превращение» (2015 г.), «Спасти Пушкина» (2017 г.). У дистрибьютора также имеется сеть «Каро», включающая 29 кинотеатров с 233 кинозалами ${ }^{6}$.

Прокатчик «Наше Кино» основан производственными компаниями «Профит» и «СТВ», занимается дистрибуцией фильмов компанией-основателей и других производителей, наиболее успешные - это анимационные франшизы «Три богатыря» и «Иван Царевич и Серый волк» производства «Мельница» и «СТВ», «Салют-7» (2017 г.) производства «СТВ», «Ледокол» (2016 г.) производства «Профит». Количество фильмов в прокате в 2015-2017 гг. составило 14, 19 и 10 соответственно.

«Вольга» занимается только дистрибуцией как российских, так и зарубежных фильмов, их количество в 2015-2017 гг. составило 18, 21, 25 соответственно. Наиболее успешные проекты в России: «Голодные игры» в сотрудничестве с Lionsgate (до 2017 г., в последующем кинокомпания сотрудничает с «Централ Партнершип»), «Плохие мамочки», «Приключения Паддингтона», «Миллионер из трущоб», «С 8 марта, мужчины», «Хатико: самый верный друг». Основным направлением рекламной деятельности выступает видеодистрибуция - распространение трейлеров кинофильмов.

Bazelevs владеет производственной компанией «ТаББаК», занимается дистрибуцией собственных и прочих фильмов, до 2010 г. пользовалась услугами других дистрибьюторов, с выходом успешной франшизы фильма собственного производства «Елки», (третья часть перешагнула отметку 1 млрд руб. по сборам) была реорганизована как независимая производственнодистрибьюторская компания. Количество выпущенных фильмов

${ }^{6}$ Невафильм research URL: http://research.nevafilm.ru/research/statistika/ (дата обращения: 01.05.2018) 
за 2015-2017 гг. составило по четыре в год, фильмы собственного производства под самостоятельной дистрибуцией: «Елки», «ОН дракон», «Самый лучший день», «Хардкор», анимация «Снежная королева»; фильмы собственного производства под дистрибуцией сторонних организаций: «Ночной дозор», «Дневной дозор», «Ирония судьбы: продолжение». Актуальным направлением деятельности компании выступает развитие партнёрства в кино с использованием маркетинговых продуктов: product placement, кросс-промо, мерчендайзинг.

«Парадиз» занимается производством и, преимущественно, дистрибуцией фильмов, за 2015-2017 гг. их выпущено 27, 35, 27 соответственно. Наиболее успешные кинокартины в прокате: «Война Богов: Бессмертные» совместно с «Наше кино», «Крым», «Помпеи», «Обитель зла», «Рэд», «Области тьмы», «All inclusive, или все включено!», собственного производства: «Платон», «Сволочи». Прокатчик активно занимается дистрибуцией на TB, VoD, DVD.

Кинокомпания «Уолт Дисней», рекордсмен по кассовым сборам мировой киноиндустрии, является крупнейшим дистрибьютором в России, занимается прокатом собственных фильмов, проектов совместного производства, а также продукции прочих производителей. На территории России функционирует как совместное предприятие в объединении с «Сони Пикчерс». В отечественный прокат было выпущено в общей сложности более 225 фильмов, 28 из которых заработали более 1 млрд руб. каждый. Самые кассовые собственные проекты: «Пираты Карибского моря: Мертвецы не рассказывают сказки», «Зверополис», «Мстители: Война Бесконечности», «Звёздные войны: Пробуждение силы», «Железный человек-3», «Алиса в стране чудес», «Холодное сердце», «Малефисента»; «Джуманджи: зов джунглей» и «Люди в черном-3» от «Сони Пикчерс». Проекты совместного производства с отечественными компаниями пользовались большой популярностью у российских зрителей, наиболее успешные из них: «Последний богатырь» в партнерстве с «ВБД Груп», «Сталинград» при участии «Арт Пикчерс Студия» и «Нон-Стоп Продакшн», «Лед» и «Притяжение» производства «Арт Пикчерс Студия».

«Юниверсал Пикчерз»-второй по величине представитель зарубежной кинопродукции, один из крупнейших в мировой 
киноиндустрии с многожанровыми проектами. В копилке прокатчика имеется 13 фильмов, кассовые сборы которых превысили 1 млрд руб. в российском прокате. Наиболее известные проекты и франшизы: «Форсаж», «Гадкий Я - Миньоны» «Тайная жизнь домашних животных», «Мир Юрского периода», «Мадагаскар» «Шрэк», «Неудержимые», «Мумия». Компания активно сотрудничает с отечественными кинопроизводителями, совместно реализованные фильмы стали весьма успешными: «Вий» производства MGE, «Я худею» вместе с киностудией «Друг друга», «Духless» в партнерстве с «Арт Пикчерс Студия», «28 панфиловцев» производства Libyan Palette Studios, «День выборов-2» с кинокомпанией «Стрела».

Можно сделать вывод о преобладании зарубежных фильмов в прокате и сложности конкурирования с иностранными производителями в спектре реализуемых кинопроектов. Это подрывает финансовую самостоятельность национальной киноиндустрии и подталкивает государство к применению стимулирующих мер для отечественных кинокомпаний.

С целью оценки последствий возможной сделки «Уолт Дисней» и «20-й век Фокс» приведем финансовую и рыночную активность каждой из анализируемых компаний в сопоставимые величины. Для этого воспользуемся методом интервальных балльных оценок с максимальной оценкой в 5 и градацией в 0,25 баллов, ранжируя значения в зависимости от величины двух критериев (табл. 2).

Финансовый аспект - отражает способность аккумулировать прокатные доходы за определенное число проектов, вычисляется путем деления совокупных кассовых сборов прокатчика за период на количество выпущенных фильмов.

Рыночный аспект - характеризует конкурентоспособность фирмы, показывает степень рыночной устойчивости и стабильности удельного веса сборов в изменяющемся совокупном результате, определяется динамикой доли фирмы на рынке сопряженно с рассчитанными показателями рыночной концентрации за анализируемый период: индекс Херфиндаля-Хиршмана = $2628 / 2806 / 2473$, коэффициент Джини $=0,570 / 0,571 / 0,513$, индекс Холла-Тайдмана $=0,258 / 0,259 / 0,228$, дисперсия рыночных долей $=0,032 / 0,0355 / 0,0298$. 
Таблица 2. Балльная оценка рыночной активности дистрибьюторов в 2015-2017 rr.

\begin{tabular}{|c|c|c|c|c|c|c|c|}
\hline \multirow{2}{*}{ Дистрибьютор } & \multicolumn{2}{|c|}{2015} & \multicolumn{2}{|c|}{2016} & \multicolumn{2}{|c|}{2017} & \multirow{2}{*}{ Bcero } \\
\hline & $\Phi / \mathbf{a}$ & $\mathbf{P} / \mathbf{a}$ & $\Phi / \mathbf{a}$ & $\mathbf{P} / \mathbf{a}$ & $\Phi / \mathbf{a}$ & $\mathbf{P} / \mathbf{a}$ & \\
\hline «Уолт Дисней» / «20-й век Фокс» & 4 & 4,5 & 3,75 & 4,5 & 4,5 & 4,25 & 25,5 \\
\hline «Юниверсал Пикчерз» & 4 & 3,5 & 2,75 & 2,75 & 3,75 & 3 & 19,75 \\
\hline «Каро Премьер» / «Каропрокат» & 3 & 3 & 3 & 3,25 & 3,5 & 3 & 18,75 \\
\hline «Централ Партнершип» & 3 & 3 & 3 & 3,25 & 3 & 3 & 18,25 \\
\hline «Наше Кино» & 2 & 2 & 1,5 & 1,5 & 2 & 2,5 & 11,5 \\
\hline «Вольга» & 1,5 & 1,75 & 0,5 & 1 & 1 & 1,5 & 7,25 \\
\hline Bazelevs & 2 & 1,5 & 1,75 & 1 & 2,25 & 1,5 & 10 \\
\hline «Парадиз» & 0,5 & 1 & 0,5 & 1 & 0,5 & 1 & 4,5 \\
\hline
\end{tabular}

Источник: составлена на основе балльной оценки рыночной активности компаний.

Воспользуемся формулой Стерджесса для разделения дистрибьюторов на уровни власти:

$$
\begin{array}{l|l|l}
m=1+3,322 \times \lg (n) & \begin{array}{l}
m=1+3,322 \times \lg (8)= \\
3,9898 \approx 4
\end{array} & \begin{array}{l}
\text { m-число } \\
\text { интервалов, } \\
\mathbf{i}-\text { шаг } \\
\text { интервала, } \\
\text { n- количество } \\
\text { фирм. }
\end{array}
\end{array}
$$

I уровень: $20,25 \leq \mathrm{x} \leq 25,5-$ «Уолт Дисней»;

II уровень: $15 \leq \mathrm{x}<20,25$ - «Юниверсал Пикчерз», «Каро Премьер» / «Каропрокат», «Централ Партнершип»;

III уровень: 9,75 $\leq$ x $<15-$ «Наше Кино», Bazelevs;

IV уровень: 4,5 $\leq$ x $<$ 9,75 - «Вольга», «Парадиз».

Таким образом, компания «Уолт Дисней» является ведущим дистрибьютором на рынке с большим отрывом от всех остальных, ранг ее конкурентоспособности существенно больше, чем у отечественных фирм. Несмотря на приблизительно равную величину рыночной активности прокатчиков II уровня, «Юниверсал Пикчерз» достигает этих результатов при меньшем числе реализованных проектов, что говорит о низкой доходности определенной части российских фильмов. Следует отметить работу компании Bazelevs, которая имеет высокие финансовые результаты даже при реализации небольшого числа кинопроектов.

Анализ демонстрирует тенденцию к снижению концентрирования кассовых сборов в 2017 г., на что повлиял выпуск ряда крупнобюджетных российских фильмов, ставших коммерчески 
успешными. Однако направление вектора развития киноиндустрии в прогнозном периоде может изменить намечающаяся сделка компаний «Уолт Дисней» и «20-й век Фокс», благодаря которой произойдет не только увеличение доли на рынке, но и диверсификация портфеля кинопроектов фирмы «Дисней». Ранее она концентрировала усилия на двух основных сегментах:

1) анимационное (мультипликационное) кино - классический жанр, первичный в истории зарождения и развития компании, ядро ее деловой репутации;

2) фантастика и фэнтези - через дочерние фирмы Lucasfilm (франшиза «Звездные войны») и Marvel Studios (супергеройское кино франшизы «Кинематографическая Вселенная Марвел»), пересъемки анимации в кинофильмы и др.

В случае приобретения компании «20-й век Фокс» «Дисней» сможет не только расширить уже освоенные жанры (путем получения прав на такие франшизы, как «Аватар», «Симпсоны», «Ледниковый период», «Люди Икс», «Чужой/Хищник» и др.), но и перейти к новым сегментам рынка киноиндустрии: мелодрамы, комедии, приключенческие боевики, кино категории «18+» и т.д. Таким образом, влияние фирмы «Дисней» на кинобизнес многократно возрастет, что приведет к увеличению его доли как на мировом, так и на локальных рынках. По нашим оценкам, потенциал значения удельного веса в кассовых сборах российской индустрии в течение трех лет после завершения сделки составит 48-50\%, также возникнут предпосылки для трансформации отечественной киноиндустрии в квазиконкурентный рынок.

Усиление концентрации грозит появлением сдвигов в предпочтениях независимых производителей: они будут заинтересованы в сотрудничестве с крупными прокатчиками, которые смогут обеспечить максимально полное распространение фильма. В связи с этим игроки IV уровня и ниже будут вынуждены пойти на демпинг дистрибьюторских услуг с целью сохранения своей ниши, их удельный вес в киноиндустрии будет снижаться, а высвободившаяся часть поделится между лидерами рынка. Что касается судьбы прокатчиков III уровня, все будет зависеть в первую очередь от успешности реализации собственных проектов: в случае выпуска кассовых фильмов фирмы смогут остаться на плаву и сохранить свою нишу, при ином варианте они будут 
вынуждены присоединиться к более крупным игрокам. Следовательно, ядром киноиндустрии станут компании I и II уровней, которые в сумме смогут концентрировать 90-95\% всех кассовых сборов (в 2017 г. на их долю приходилось 85\%).

Получаемый эффект соответствует признакам квазиконкурентных рынков: наличие небольшого количества крупных фирм в сочетании с высокой концентрацией рынка, отсутствие значительных барьеров для входа, невозможность установить монопольную власть и необходимость конкурентной борьбы [Amavilah, 2012]. Нетрудно предположить, что в этом случае прокатчики будут отдавать предпочтение более прибыльным кинопроектам - иностранным, и отечественное кинопроизводство пострадает.

\section{Как защитить отечественный кинематограф: предложения и выводы}

В такой ситуации государственная финансовая помощь не сможет поддерживать перманентную конкурентоспособность отечественной киноиндустрии, а введение жестких ограничительных мер (например, квот на иностранные фильмы) может привести к упадку отрасли в целом из-за неспособности отечественного кинопроизводства полностью удовлетворить спрос потребителей в аспектах качества кино и многообразия жанров. Следовательно, актуален поиск путей защиты отечественной киноиндустрии, которые не будут сдерживать развитие отрасли в целом.

На основе проведенного анализа выделим три проблемы, преодоление которых будет иметь первостепенное значение:

1) низкая инвестиционная привлекательность российских кинопроектов;

2) ограниченность финансовых ресурсов;

3) сложность конкурирования с иностранными компаниямилидерами на рынке.

Помимо ранее названных причин низкой инвестиционной привлекательности российского кино, существуют и такие, как намеренное занижение итогового финансового результата в целях минимизации налогового бремени, отсутствие у потенциальных инвесторов полной информации о всех денежных потоках по кинопроекту. Из-за приверженности отечественных компаний к политике минимизации налогов теряется их инвестиционная 
привлекательность, следовательно, первым шагом должен стать переход к политике увеличения инвестиционной привлекательности, в основе которой лежат принципы прозрачности, открытости и адекватности предоставляемой информации.

Относительно второй проблемы использование методики определения финансового результата по кинопроекту, предложенной автором в этой статье, позволит раскрыть преимущества от вложения капитала в проект, а расчет показателя CoCR даст представление об уровне рентабельности затрат. При этом для отечественных компаний главной задачей станет обеспечение доступности такой информации для инвесторов, чтобы те смогли оценить все возможные риски и потенциальную прибыльность инвестиций. Также введение временных налоговых преференций на прибыль от реализации кинопроекта в форме необлагаемого минимума позволит кинопроизводителям повысить доходность собственной деятельности и, соответственно, ее инвестиционную привлекательность.

Для ликвидации барьеров, вызванных ограниченностью ресурсов и конкуренцией с иностранными прокатчиками предлагаем применение практики квотирования. Как отмечалось ранее, ограничение зарубежного контента не приведет к положительному эффекту в целом, поэтому предлагаемые квоты не повлияют на количество реализуемых проектов. Ограничения будут касаться только дистрибуции фильмов, т.е. каждой иностранной компании будет разрешено осуществлять самостоятельный прокат лишь определенной части проектов (через собственных дистрибьюторов), остальные должны будут реализовываться через отечественных прокатчиков.

Принятие такого решения станет импульсом для формирования нового источника финансовых ресурсов - дистрибьюторской доли (производитель будет оплачивать услуги прокатчика); благодаря принятию прав на распространение иностранных фильмов отечественные прокатчики смогут самостоятельно регулировать даты показа фильмов в кинотеатрах, чтобы выигрывать в условиях конкуренции. Такие квоты должны устанавливаться не на весь портфель кинопроектов, а по его сегментам (жанрам), так как в первом случае зарубежные корпорации могут намеренно передать права на прокат наименее рентабельных фильмов для минимизации премии дистрибьютора. Подобные 
меры потенциально смогут одновременно решить несколько проблем: повысить финансовую самостоятельность производителей за счет реинвестирования полученной дистрибьюторской доли и в то же время благодаря умеренному характеру не будут ограничивать темпы развития киноиндустрии, способствуют сглаживанию конкуренции с лидерами рынка.

С целью минимизации утечки капитала за рубеж через каналы киноиндустрии целесообразно установить лимит значения кинотеатральной ренты для иностранных дистрибьюторов, при этом не настолько низкий, как в Китае, чтобы избежать снижения интереса со стороны иностранных корпораций. Оптимальные размеры такого ограничения необходимо определять исходя из среднего показателя размера прокатной ренты по отечественным компаниям, предел должен быть равным или меньше его.

Проведенные исследования позволяют комплексно оценить ситуацию в российской киноиндустрии и устранить барьеры развития отечественного кинематографа, предложенные способы их преодоления отвечают вызовам, сдерживающим рост отрасли. Представленная методика определения финансового результата по кинопроекту дает более полное представление о видах денежных потоков и схемах их распределения, что повышает точность и упрощает процесс анализа инвестиционной привлекательности.

\section{Литература}

Антонов А.П. Кинобизнес в России и США: стратегия, история и перспективы // Экономический журнал. 2009. № 2. С. 135-143.

Аракелян А.М. Механизмы государственной поддержки услуг киноиндустрии в Российской Федерации на основе международного опыта // Сервис plus. 2017. T. 11. № 3. C. 47-53 DOI: 10.22412/1993-7768-11-3-6

Аракелян А.М. Формирование условий повышения инвестиционной привлекательности киноотрасли в России // Сервис plus. 2016. № 2. С. 74-79. DOI: $10.12737 / 19459$

Борисенко О.А. Особенности финансирования кинопроизводства в странах с развитой киноиндустрией // Современные проблемы науки и образования. 2015. № 1-1. URL: https://science-education.ru/ru/article/view?id=19272 (дата обращения: 16.01.2018).

Карпушин Е.С., Кулакова А.И. Российская киноиндустрия как часть экономики страны // ЭКО. 2015. № 8. С. 181-189 
Ковтонюк Ф. В. Социально-экономические особенности и этапы исторического развития киноиндустрии на примере США и России // Экономический журнал. 2016. Т. 41. № 41. С. 126-150

Седых И.А. Киноиндустрия России. М: Высшая школа экономики, 2017. $68 \mathrm{c}$.

Спивакова К.С, Аракелян А. М. Анализ современного состояния отечественной киноиндустрии // Сервис plus. 2016. № 3. C. 42-59 DOI: 10.12737/21122

Спивакова К. С. Внедрение практики completion bond как актуальная проблема развития кинопроизводства в России // Сервис в России и за рубежом. 2013. № 4 (42). С. 129-137

Тевелева О.В., Татарников А.С. Зарубежный и отечественный опыт финансирования кинопроизводства и диверсификации рисков при инвестировании в кино // Финансовая аналитика: проблемы и решения. 2013. № 40 (178). C. $32-40$

Чудкова А.В. Международное совместное кинопроизводство как фактор повышения конкурентоспособности национальной киноиндустрии в условиях глобализации и интернационализации мирового кинорынка // Вестник университета. 2013. № 11. С. 64-68.

Эпштейн Э. Экономика Голливуда: На чем на самом деле зарабатывает киноиндустрия / Пер. с англ. М: Альпина Паблишер, 2011. 212 с.

Amavilah V.H. Baumol, Panzar and Willig's Theory of Contestable Markets and Industry Structure: A Summary of Reactions / MPRA Paper 41974, University Library of Munich, Germany. 2012. URL: https://mpra.ub.uni-muenchen.de/41974/ (дата обращения: 16.05.2018)

Статья поступила 18.07.2018.

\section{Summary}

Shinakhov A.A. Kabardino-Balkarian State university named after H. M. Berbekov, Nalchick

\section{The Film Industry Today: Impulses and Barriers of Development}

The article describes modern situation in the film industry of Russia, taking into account the main problems for it development. It touches upon the features of motion picture project realization considering their cash flows allocation schemes. Scientific works of domestic and foreign scientists in the field of film production and movie financing is the ground of the research. The consequences of a possible deal between the largest film companies Walt Disney and 20 Century Fox for Russian cinema have been studied. The analysis of the situation in the industry was carried out by using the dynamics of the box office and market concentration, as well as the ranking method. In order to support domestic film production, the following steps were proposed: quoting of foreign distributors share in the market, maximization of investment attractiveness based on the openness of information about the project using the proposed method, introduction of the cinema-theatrical rent's limiting value for foreign distributors.

Film industry; box office; cinema-theatrical rent; cash flows; distributor; market structure; motion picture project 


\section{References}

Antonov A. P. (2009). Kinobiznes v Rossii i SShA: strategija, istorija i perspektivy. Jekonomicheskij zhurnal [Economic journal]. No. 2. Pp. 135-143 (In Russ.)

Arakeljan A. M. (2017). Mehanizmy gosudarstvennoj podderzhki uslug kinoindustrii v Rossijskoj Federacii na osnove mezhdunarodnogo opyta. Servis plus [Service plus]. Vol. 11. No. 3. Pp. 47-53 (In Russ.). DOI: 10.22412/19937768-11-3-6

Arakeljan A. M. (2016). Formirovanie uslovij povyshenija investicionnoj privlekatel'nosti kinootrasli v Rossii. Servis plus [Service plus]. No. 2. Pp. 74-79 (In Russ.). DOI: 10.12737/19459

Borisenko O.A. (2015). Osobennosti finansirovanija kinoproizvodstva v stranah s razvitoj kinoindustriej. Sovremennye problemy nauki i obrazovanija [Modern problems of science and education]. No. 1-1. (In Russ.). Available at: https://scienceeducation.ru/ru/article/view?id=19272 (accessed: 16.01.2018).

Karpushin E.S., Kulakova A.I. (2015). Rossijskaja kinoindustrija kak chast' jekonomiki strany. ECO [ECO]. No. 8. Pp. 181-189 (In Russ.).

Kovtonjuk F. V. (2016). Social'no-jekonomicheskie osobennosti i jetapy istoricheskogo razvitija kinoindustrii na primere SShA i Rossii. Jekonomicheskij zhurnal [Economic journal]. Vol. 41. No. 41. Pp. 126-150 (In Russ.)

Sedykh I.A. (2017). Kinoindustrija Rossii. M: Vysshaja shkola jekonomiki Publ. 68 p. (In Russ.)

Spivakova K.S, Arakeljan A.M. (2016). Analiz sovremennogo sostojanija otechestvennoj kinoindustrii. Servis plus [Service plus]. No. 3. Pp. 42-59 (In Russ.) DOI: $10.12737 / 21122$

Spivakova K.S. (2013). Vnedrenie praktiki completion bond kak aktual'naja problema razvitija kinoproizvodstva v Rossii. Servis $v$ Rossii i za rubezhom [Services in Russia and abroad]. No. 4 (42). Pp. 129-137 (In Russ.)

Teveleva O.V., Tatarnikov A.S. (2013). Zarubezhnyj i otechestvennyj opyt finansirovanija kinoproizvodstva i diversifikacii riskov pri investirovanii $\mathrm{v}$ kino. Finansovaja analitika: problemy $i$ reshenija [Financial analytics: science and experience]. No. 40 (178). Pp. 32-40 (In Russ.)

Chudkova A.V. (2013). Mezhdunarodnoe sovmestnoe kinoproizvodstvo kak faktor povyshenija konkurentosposobnosti nacional'noj kinoindustrii v uslovijah globalizacii i internacionalizacii mirovogo kinorynka. Vestnik universiteta [Vestnik universiteta]. No. 11. Pp. 64-68 (In Russ.)

Epshtejn E. (2011). Ekonomika Gollivuda: Na chem na samom dele zarabatyvaet kinoindustrija. Moscow. Al'pina Pablisher Publ. 212 p. (In Russ.)

Amavilah, V. H. (2012). Baumol, Panzar, and Willig's Theory of Contestable Markets and Industry Structure: A Summary of Reactions. MPRA Paper 41974, University Library of Munich, Germany. Available at: https://mpra.ub.uni-muenchen. de/41974/ (accessed: 16.05.2018). 